\title{
Persistência do Herbicida S-Metolachlor Associado ao Glyphosate ou Paraquat em Plantio Direto ${ }^{1}$
}

\author{
Persistence of S-Metolachlor Associated to Glyphosate or Paraquat Under No-Tillage
}

\author{
NUNES, A.L. ${ }^{2}$ e VIDAL, R.A. ${ }^{3}$
}

\begin{abstract}
RESUMO - A associação de herbicidas dessecantes com efeito residual é comum entre os agricultores no manejo das áreas sob semeadura direta. Essa prática permite a dessecação da cultura de inverno a ser utilizada como cobertura morta e, também, evita a reinfestação por plantas daninhas na cultura de verão durante parte de seu ciclo. O objetivo do presente trabalho foi determinar a persistência do herbicida residual S-metolachlor, quando associado com os herbicidas dessecantes glyphosate ou paraquat, aplicados sobre cobertura vegetal. O trabalho foi realizado a campo na Estação Experimental Agronômica da Universidade Federal do Rio Grande do Sul (EEA/UFRGS) e em câmara de crescimento da Faculdade de Agronomia da UFRGS, sob Argissolo Vermelho distrófico típico, contendo 28\% de argila. O delineamento experimental foi de blocos casualizados, com quatro repetições, sendo os tratamentos distribuídos em parcelas subdivididas. Nas parcelas principais, foram alocados os herbicidas dessecantes paraquat $\left(600 \mathrm{~g} \mathrm{ha}^{-1}\right)$ ou glyphosate $\left(720 \mathrm{~g} \mathrm{ha}^{-1}\right) \mathrm{e}$, nas subparcelas, o herbicida residual $\mathrm{S}$-metolachlor $\left(2.800 \mathrm{~g} \mathrm{ha}^{-1}\right)$ associado ou aplicado seqüencialmente aos herbicidas dessecantes, além de uma testemunha contendo apenas herbicida dessecante, sem aplicação do herbicida residual. A persistência do S-metolachlor é maior na presença do paraquat do que na do glyphosate. Não há diferença entre aplicação simultânea e seqüencial dos herbicidas dessecantes e residuais.
\end{abstract}

Palavras-chave: bioensaio, cinética de dissipação, meia-vida, residual.

\begin{abstract}
Non-selective and residual herbicides are commonly associated by farmers to manage no-tillage areas. This practice allows controlling the winter crop to be used as cover crop and to avoid weed reinfestation during part of the summer crop cycle. The objective of this work was to determine the persistence of the residual herbicide $S$ metolachlor when associated to the nonselective herbicides paraquat and glyphosate. The work was carried out under field conditions at the Estação Experimental Agrônomica of the Universidade Federal do Rio Grande do Sul (EEA) UFRGS), and in a growth chamber of the Faculdade de Agronomia of the UFRGS under typical Dystrophic Red Argisol composed by 28\% clay. The experiment was arranged in a randomized block design with four replications, with the treatments distributed in split plots . The non-selective herbicides (paraquat, $600 \mathrm{~g} \mathrm{ha}^{-1}$ or glyphosate $720 \mathrm{~g} \mathrm{ha}^{-1}$ ) were applied in the main plots, and the residual herbicide S-metolachlor (2.800 $\left.\mathrm{g} \mathrm{ha}^{-1}\right)$ in the sub plots, associated or sequentially applied with the non-selective herbicides, plus one control with only non-selective herbicides being applied. The persistence of S-metolachlor is higherin the presence of paraquat when compared to glyphosate. No difference was found between simultaneous and sequential applications of the non-selective and residual herbicides.
\end{abstract}

Keywords: bioassay, dissipation kinetics, half-life, residual.

1 Recebido para publicação em 31.7.2007 e na forma revisada em 27.3.2008.

2 Engo-Agro , Mestre, Curso de Agronomia, Universidade Tecnológica Federal do Paraná - UTFPR, Campus Pato Branco, Via do Conhecimento, km 01, 85503-390, Pato Branco-PR; ${ }^{3}$ Engo-Agr ${ }^{0}$, Ph.D., Faculdade de Agronomia, Universidade Federal do Rio Grande do Sul - UFRGS, Av. Bento Gonçalves, 7712, Caixa Postal 15100, 91540-000, Porto Alegre-RS. 


\section{INTRODUÇÃO}

O uso da associação de herbicida dessecante e residual é comum entre agricultores, no manejo de áreas sob plantio direto, na região Sul do Brasil. Essa prática cumpre duas finalidades: dessecar a cultura de inverno que será utilizada como cobertura morta e evitar a reinfestação de plantas daninhas na cultura de verão durante parte de seu ciclo.

O sistema de semeadura direta tem como princípio a formação de cobertura vegetal sobre a superficie do solo, o que permite suprimir a germinação e a emergência de plantas daninhas (Burgos \& Talbert, 1996; Theisen et al., 2000). Contudo, a manutenção de palha sobre a superfície promove alterações que afetam a dinâmica dos herbicidas aplicados ao solo (Levanon et al., 1993; Weed et al., 1995; Ferri \& Vidal, 2003). Assim, a permanência da cobertura sobre a superfície do solo pode, simultaneamente, reduzir o potencial de infestação da comunidade infestante, como também dificultar o desempenho de herbicidas, uma vez que os principais componentes da dinâmica de herbicidas na palha são a transposição do produto através desta e a própria dinâmica de molhamento e lavagem da palha pela água das chuvas (Maciel \& Velini, 2005).

A atividade e a permanência do herbicida acetochlor foram reduzidas com o aumento da cobertura vegetal na superficie do solo, o que levou à redução no controle de plantas daninhas (Ferri et al., 2002, 2006). Metolachlor aplicado sobre cobertura morta formada por Vicia villosa teve menor eficiência no controle de plantas daninhas quando comparado ao sistema sem cobertura, devido à redução da concentração de metolachlor no solo, ocasionada pela cobertura da superficie (Teasdale et al., 2003). A disponibilidade do herbicida trifluralin no solo foi maior no sistema de semeadura convencional, quando comparado ao sistema de semeadura direta (Chauhan et al., 2006). Isso ocorre, provavelmente, devido ao fato de que a cobertura vegetal possui maior capacidade de sorção de herbicidas que o solo (Reddy et al., 1995; Dozier et al., 2002). Entretanto, metribuzin aplicado sobre cobertura morta de milheto (Pennisetum americanum) controlou, tanto em pré como em pós-emergência, as espécies Ipomoea grandifolia e Sida rhombifolia, mesmo sem a ocorrência de chuvas após a aplicação (Godoy et al., 2007).

O herbicida S-metolachlor é um composto não-ionizável, que pertence ao grupo químico das acetamidas. É aplicado, em pré-emergência ou pré-plantio incorporado, para controle de algumas monocotiledôneas e dicotiledôneas, atuando como inibidor da parte aérea das plantas, de forma seletiva para as culturas do milho e soja (Ahrens, 1994; Vidal \& Fleck, 2001). O produto formulado $D_{U A L}{ }^{\circledR}$ é formado por dois isômeros $\mathrm{R}$ e dois $\mathrm{S}$ de metolachlor, que estão presentes em proporções semelhantes no herbicida. Os isômeros $\mathrm{S}$ apresentam maior atividade herbicida do que os isômeros $\mathrm{R}$ (Moser et al., 1982). Com o conhecimento dessa propriedade, foi desenvolvido novo sistema catalítico, que produziu uma formulação enriquecida ( $>80 \%$ ) com os isômeros $\mathrm{S}$, a qual foi denominada S-metolachlor, originando o produto formulado DUAL GOLD ${ }^{\circledR}$ (Blaser \& Spindler, 1997; Spindler et al., 1998). Estudos demonstram similaridade entre metolachlor e S-metolachlor quanto ao seu comportamento no ambiente (O'Connell et al., 1998).

Há grande variabilidade no tempo de permanência do S-metolachlor no solo. Estudos realizados em laboratório mostraram que a meia-vida do S-metolachlor no solo varia entre 6 e 100 dias, dependendo das condições em que a pesquisa é realizada (O'Connell et al., 1998; Dinelli et al., 2000; Seybold et al., 2001; Mersie et al., 2004; Accinelli et al., 2005; Ma et al., 2006). Sob condições de campo, trabalhos evidenciaram que a meia-vida do metolachlor varia entre 8 e 85 dias (Burgard et al., 1993; O'Connell et al., 1998; Dinelli et al., 2000; Laabs et al., 2002). Contudo, essas determinações ocorreram sem a presença do herbicida dessecante.

A aplicação conjunta de glyphosate e atrazine no solo estimulou maior atividade microbiana do que quando se aplicou somente atrazine, mas a degradação deste foi similar entre os tratamentos atrazine e glyphosate + atrazine, com exceção de alguns tratamentos, onde glyphosate aumentou ligeiramente a degradação de atrazine (Haney et al., 2002). Entretanto, em trabalho similar, a presença em grande quantidade do glyphosate $\left(129 \mathrm{mg} \mathrm{kg}^{-1}\right.$ de solo) estimulou a atividade microbiana, que, simultaneamente, inibiu a degradação do 
herbicida atrazine aos oito dias após a aplicação deles em associação, mostrando que a degradação do atrazine está inversamente correlacionada com a atividade microbiana e com as doses de glyphosate aos oito dias após a aplicação (Krutz et al., 2003). Tuffi Santos et al. (2005) e Ferreira et al. (2006), trabalhando com exsudação de glyphosate em Brachiaria decumbens e Lolium multiflorum, respectivamente, não observaram alterações na atividade microbiana em solos argilosos devido ao uso de glyphosate.

Além da interação entre herbicida dessecante e residual, interações entre herbicidas residuais aplicados em associação influenciam a degradação destes no solo. O herbicida atrazine retardou a degradação do herbicida cyanazine em extratos celulares (Gebendinger \& Radosevich, 1999). A mineralização e a degradação do atrazine $\left(175 \mathrm{mg} \mathrm{kg}^{-1}\right.$ solo) por microrganismos foram atrasadas por altas concentrações de metolachlor (182 mg kg-1 solo), mas não por trifluralin (165 mg kg-1 solo) (Moorman et al., 2001). Entretanto, os herbicidas atrazine e pendimethalin, na concentração de $50 \mathrm{mg} \mathrm{kg}^{-1}$ de solo, não tiveram efeitos na degradação do metolachlor (Anhalt et al., 2000). Ainda, a biomassa microbiana e o quociente metabólico, a campo, foram maiores em amostras de solo submetidas à aplicação de atrazine (1.500 $\left.\mathrm{g} \mathrm{ha}^{-1}\right)$ ou à mistura deste com nicosulfuron ( 4 e $32 \mathrm{~g} \mathrm{ha}^{-1}$ ), em comparação a amostras de solo não tratadas, aos sete dias após a aplicação destes (Jakelaitis et al., 2007). O objetivo do presente trabalho foi determinar a persistência do herbicida residual S-metolachlor quando associado aos dessecantes glyphosate ou paraquat, aplicados sobre cobertura vegetal.

\section{MATERIAL E MÉTODOS}

O trabalho foi instalado a campo no dia 21 de outubro de 2005, na Estação Experimental Agronômica da Universidade Federal do Rio Grande do Sul (EEA/UFRGS), localizada em Eldorado do Sul, região fisiográfica da Depressão Central do RS, e em câmara de crescimento da Faculdade de Agronomia da Universidade Federal do Rio Grande do Sul (UFRGS), localizada no município de Porto Alegre. O solo da EEA/UFRGS é classificado, segundo o Sistema Brasileiro de Classificação de Solos (Embrapa,
1999), como Argissolo Vermelho distrófico típico, com $28 \%$ de argila.

O delineamento experimental foi de blocos casualizados, com quatro repetições, sendo os tratamentos distribuídos em parcelas subdivididas. Nas parcelas principais foram alocados os herbicidas dessecantes paraquat (600 $\mathrm{g} \mathrm{ha}^{-1}$ ) ou glyphosate (720 $\left.\mathrm{g} \mathrm{ha}^{-1}\right)$ e, nas subparcelas, o herbicida residual S-metolachlor (2.800 $\left.\mathrm{g} \mathrm{ha}^{-1}\right)$ aplicado seqüencialmente ou em associação com os herbicidas dessecantes, além de uma testemunha sem aplicação de herbicidas residuais. A associação dos herbicidas dessecante e residual caracterizou-se pela solubilização de ambas as formulações em água, simultaneamente, seguindo-se a sua aplicação. A aplicação seqüencial caracterizou-se pela solubilização das formulações em recipientes distintos e sua aplicação com intervalo de cinco minutos. Cada unidade experimental mediu $2 \times 5 \mathrm{~m}$, com área útil de $1,5 \times 4 \mathrm{~m}$.

Os herbicidas foram pulverizados com equipamento costal, pressurizado com $\mathrm{CO}_{2}$, à pressão constante de $200 \mathrm{kPa}$, contendo bicos tipo leque 8001 , distantes entre si em $0,50 \mathrm{~m}$ na barra de $1,5 \mathrm{~m}$ de largura, com volume de calda de $110 \mathrm{~L} \mathrm{ha}^{-1}$. A aplicação foi realizada das 16 às 16h55. No momento da aplicação a temperatura média do ar era de $27^{\circ} \mathrm{C}$, e a umidade relativa média do ar, de $71 \%$. A pulverização foi feita sobre cobertura vegetal viva, formada por plantas de Lolium multiflorum que estavam na fase de floração. A matéria seca total da cobertura viva foi de $2.800 \mathrm{~kg} \mathrm{ha}^{-1}$. Na área experimental a campo, procedeu-se a coletas de amostras de solo para, posteriormente, conduzir bioensaios em câmara de crescimento. Inicialmente, o material vegetal foi retirado da superficie e, em seguida, as amostras de solo foram coletadas nos primeiros $5 \mathrm{~cm}$ do perfil do solo. As amostras foram acondicionadas em copos plásticos com capacidade de $300 \mathrm{~cm}^{3}$ e, logo após, armazenadas a $-5^{\circ} \mathrm{C}$. A coleta das amostras de solo foi distribuída no tempo, aos 1, 5, 10, 14, 21, 27 e 35 dias após a aplicação (DAA) dos herbicidas a campo.

Após as coletas de solo, distribuídas em diferentes intervalos após a aplicação dos herbicidas no campo (1 a 35 DAA), realizou-se bioensaio em câmara de crescimento, utilizando Raphanus sativus como espécie indicadora da 
persistência dos herbicidas residuais. Três sementes pré-germinadas foram semeadas em vasos com capacidade de $300 \mathrm{~cm}^{3}$. O desenvolvimento das plantas ocorreu com temperatura média de $25,3 \pm 3,1^{\circ} \mathrm{C}$ e umidade relativa do ar de $85,4 \pm 9,8 \%$, com fotoperíodo de 12 horas e irrigação por aspersão.

No bioensaio, avaliaram-se as variáveis fitotoxicidade e estatura. A primeira foi avaliada aos sete dias após a semeadura (DAS) das plantas indicadoras nas amostras de solo coletadas em diferentes intervalos de tempo, após a aplicação dos herbicidas no campo (1 aos 35 DAA). A estatura foi avaliada aos 11 DAS, com régua milimétrica. Para fitotoxicidade, atribuíram-se notas que variaram de $0 \%$, para ausência de efeito, a 100\%, para efeito letal nas plantas.

A biodisponibilidade dos herbicidas residuais no solo foi determinada por meio de curva de calibração, utilizando a variável estatura aos 11 DAA. A elaboração da curva de calibração foi realizada semeando-se sementes pré-germinadas da planta indicadora no solo oriundo do local do experimento a campo (coletado antes da implantação) e aspergidas com $0,1,3,6,9$ e $20 \%$ da dose máxima de rótulo do herbicida S-metolachlor (1.920 $\left.\mathrm{g} \mathrm{ha}^{-1}\right)$. O desenvolvimento das plantas da curva de calibração ocorreu nas mesmas condições do bioensaio em câmara de crescimento. As curvas de calibração foram obtidas por meio do programa computacional Origin 8.0, após submeter os dados à análise da variância.

A persistência do S-metolachlor no solo foi determinada mediante a cinética de dissipação de herbicidas (Paul \& Clark, 1996), utilizando a equação 1 .

$$
\ln \left(\frac{\left[C_{f}\right]}{\left[C_{i}\right]}\right)=-k t
$$

em que $\left[C_{i}\right]$ e $\left[C_{f}\right]$ são as concentrações de herbicidas indicadas pelo bioensaio no tempo inicial e final, respectivamente; $k$, a constante de dissipação do herbicida no tempo; e $t$, o tempo. A meia-vida $\left(t_{1 / 2}\right)$ na solução do solo foi calculada pela equação 2. A [ $C_{i}$ ] foi considerada a partir da data após aplicação dos herbicidas onde houve a máxima quantidade disponivel na solução do solo, o que corresponde à menor estatura apresentada pela planta indicadora.

$$
t_{1 / 2}=\frac{0,693}{k}
$$

Os dados do bioensaio foram convertidos em porcentagem em relação à testemunha sem herbicida. Os dados provenientes da variável estatura, avaliados aos $11 \mathrm{DAS}$, da planta indicadora foram utilizados para obter a biodisponibilidade $\left(\mathrm{g} \mathrm{ha}^{-1}\right)$ dos herbicidas residuais no solo, por meio da curva de calibração. Os dados do bioensaio e da biodisponibilidade foram em seguida submetidos à análise da variância pelo teste $\mathrm{F}$. As variáveis foram analisadas por meio da comparação das médias de tratamentos pelo teste DMS a $5 \%$ de probabilidade $(P \geq 0,05)$.

\section{RESULTADOS E DISCUSSÃO}

Entre a pulverização dos herbicidas na cobertura vegetal, em associação ou em aplicação seqüencial, e a primeira coleta de solo realizada no primeiro dia após a aplicação (DAA) ocorreu precipitação de $21 \mathrm{~mm}$. Outras precipitações ocorreram até o final das coletas de solo, sendo a de maior intensidade aquela entre as coletas aos 10 e 14 DAA, de $42 \mathrm{~mm}$. Não ocorreram precipitações nos períodos entre 14 e 21 nem entre 21 e 28 DAA. A precipitação acumulada entre a aplicação dos herbicidas e a finalização do estudo, aos 35 DAA, foi de $100 \mathrm{~mm}$ (Figura 1).

Não houve diferenças significativas, nas variáveis analisadas, entre a aplicação em associação e a aplicação seqüencial ( $p>0,26$ para fitotoxicidade, $\mathrm{p}>0,35$ para estatura $\mathrm{e}$ $\mathrm{p}>0,42$ para biodisponibilidade). Devido a isso,

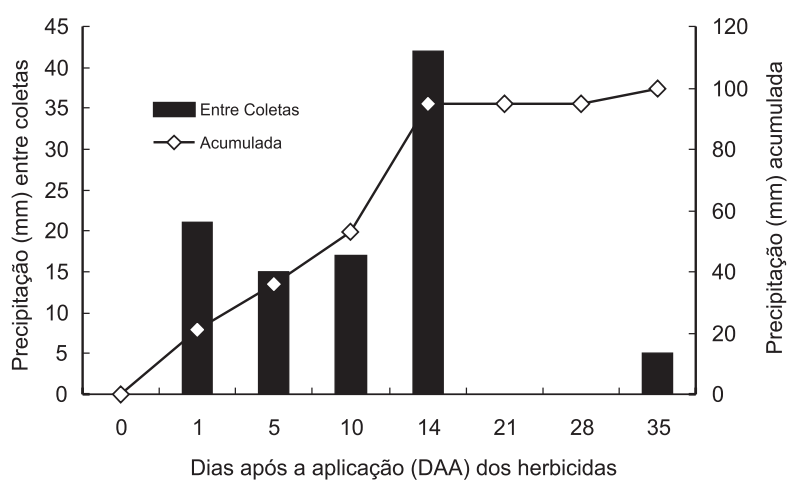

Figura 1 - Precipitação pluvial entre cada coleta (mm) e precipitação pluvial acumulada $(\mathrm{mm})$ durante o estudo. 
será apresentada a média das formas de aplicação de cada combinação de herbicidas dessecantes com S-metolachlor.

$\mathrm{Na}$ avaliação de fitotoxicidade realizada aos sete dias após a semeadura (DAS), observou-se que as plantas de nabo forrageiro apresentaram baixos sintomas de toxicidade quando semeadas no solo coletado no primeiro DAA do S-metolachlor, independentemente do herbicida dessecante utilizado (Figura 2). Isso indica que a primeira precipitação de $21 \mathrm{~mm}$ não foi suficiente para mover o S-metolachlor da cobertura vegetal para a solução do solo. Contudo, uma segunda precipitação de $15 \mathrm{~mm}$, ocorrida entre a primeira coleta de solo e a realizada aos 5 DAA, foi suficiente para mover quantidade do produto da cobertura vegetal ao solo para causar toxicidade na planta indicadora (Figura 2).

Trabalhos demonstram que de 15 a 95\% dos herbicidas aplicados podem ser intercepta-

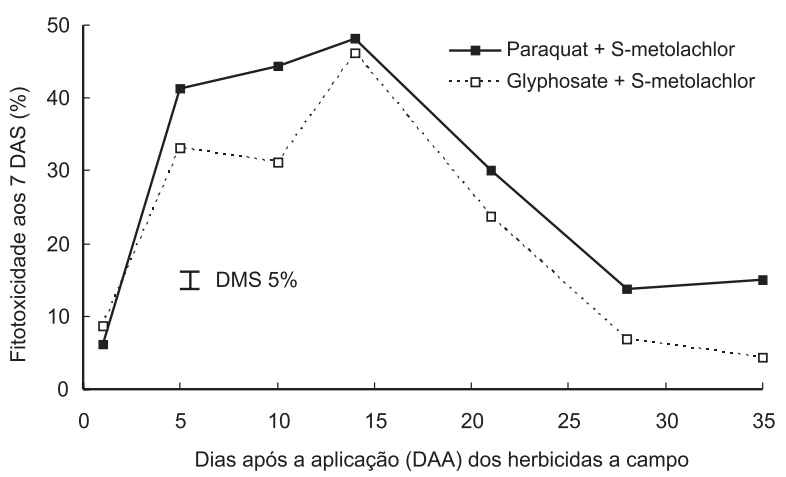

Figura 2 - Toxicidade de S-metolachlor associado a herbicidas dessecantes (paraquat e glyphosate) sobre nabo forrageiro, sete dias após a sua semeadura (DAS) em amostras de solo com até 35 dias após a aplicação (DAA) dos herbicidas a campo.

dos pela cobertura vegetal, dependendo da quantidade, do tipo e do grau de sua decomposição (Banks \& Robinson, 1982; Sorenson et al., 1991; Selim et al., 2003; Ma \& Selim, 2005). A quantidade de atrazine detectada no solo foi menor quando aplicado sobre cobertura de aveia-preta (Avena strigosa) do que em solo sem cobertura morta, pois parte do produto ficou retida na palha. Em aplicações de atrazine sobre cobertura de centeio, $30 \%$ a menos do produto atingiu o solo, comparado ao aplicado diretamente ao solo (Bauman \& Ross, 1983). A atrazine, quando aplicada sobre restos vegetais de milho (Zea mays) e aveia, ficou mais retida na palha de milho do que na de aveia (Lowder \& Weber, 1982).

Um fato interessante a respeito da adsorção dos herbicidas residuais na cobertura vegetal é que o herbicida retido pode dessorver com o tempo e manter o controle de plantas daninhas por maior período. Esse evento pode ser observado na Figura 5, onde se nota que, entre 10 e 14 DAA dos herbicidas a campo, houve aumento na biodisponibilidade do S-metolachlor quando associado ao glyphosate, após precipitação pluvial de $43 \mathrm{~mm}$.

A retenção dos herbicidas pela cobertura vegetal também é afetada pela quantidade e época de ocorrência de precipitações pluviais após a aplicação. Sobre cobertura morta de trigo, houve aumento das quantidades de metolachlor, alachlor e acetochlor na superfície do solo com o aumento da água de irrigação (Banks \& Robinson, 1986). Irrigação com 100 mm de água logo após a aplicação de atrazine removeu $87 \%$ deste herbicida da cobertura morta, mas, quando realizada sete dias após a aplicação, removeu apenas $77 \%$ do produto (Lowder \& Weber, 1982).

Em solos coletados aos 5 e 10 DAA, o Smetolachlor associado ao glyphosate causou menor fitotoxicidade do que quando associado ao paraquat (Figura 2). A diferença entre os herbicidas dessecantes não foi significativa aos 14 DAA, provavelmente devido à precipitação de $42 \mathrm{~mm}$, que deve ter deslocado S-metolachlor da cobertura vegetal para a solução do solo, sobretudo quando o S-metolachlor estava associado ao glyphosate. A partir de 14 DAA ocorreu redução da toxicidade dos herbicidas nas plantas indicadoras, e esta redução foi maior quando o S-metolachlor se associou ao glyphosate, em comparação à sua associação com paraquat (Figura 2).

$\mathrm{Na}$ avaliação de estatura realizada aos 11 DAS, as plantas de nabo forrageiro semeadas no solo coletado no primeiro DAA do S-metolachlor apresentaram estatura igual à da testemunha, independentemente do herbicida dessecante utilizado. Os resultados de estatura, assim como os de fitotoxicidade, indicam que a primeira precipitação, de $21 \mathrm{~mm}$, não foi suficiente para translocar o S-metolachlor da cobertura vegetal para a solução do solo 
(Figuras 2 e 3). Os herbicidas dessecantes podem influenciar a disponibilidade dos herbicidas residuais de duas formas. Primeiramente, através da interação entre o herbicida dessecante e a cobertura vegetal, que afeta de forma negativa ou positiva o movimento do produto residual da cobertura vegetal para a solução do solo. Em segundo lugar, o herbicida dessecante pode mudar a composição da comunidade microbiana, aumentar a biomassa e estimular a atividade microbiana no solo, o que pode inibir ou estimular a degradação dos herbicidas residuais.

Por meio de ensaio de dose-resposta, foi obtida a curva de calibração do S-metolachlor a partir da variável estatura do nabo forrageiro, avaliada aos 11 DAS. A equação de ajuste seguiu o modelo polinomial, com $\mathrm{R}^{2}$ igual a 0,93 (Figura 4). Através da curva de calibração (Figura 4) e da variável estatura do nabo forra-

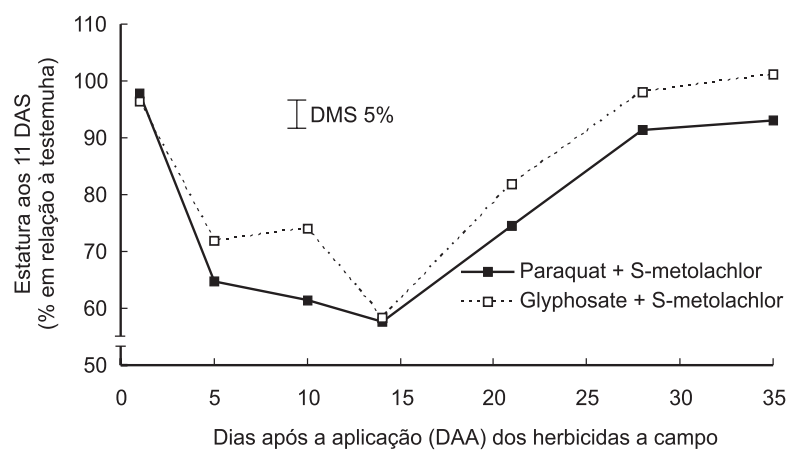

Figura 3 - Estatura (\% em relação à testemunha) do nabo forrageiro, em função do S-metolachlor associado a herbicidas dessecantes (paraquat e glyphosate), 11 dias após a sua semeadura (DAS) em amostras de solo com até 35 dias após a aplicação (DAA) dos herbicidas a campo.

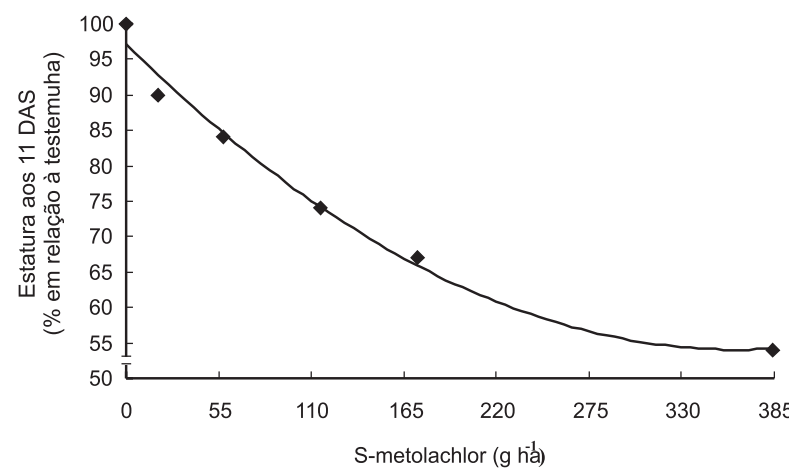

Figura 4 - Estatura (\% em relação à testemunha) do nabo forrageiro, em função de doses do herbicida S-metolachlor, 11 dias após a sua semeadura geiro, avaliada aos 11 DAS no solo coletado a campo (Figura 3), determinou-se a biodisponibilidade (Figura 5) e a meia-vida (Tabela 1) do S-metolachlor na solução do solo.

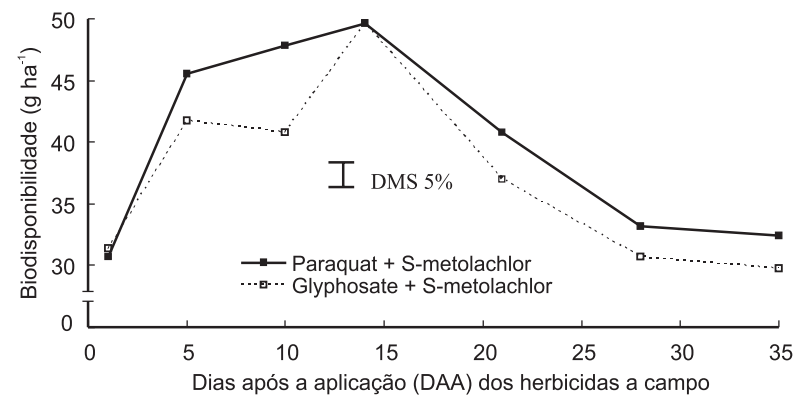

Figura 5 - Biodisponibilidade do S-metolachlor em função do herbicida dessecante (paraquat e glyphosate), obtida por meio da variável estatura, avaliada aos 11 dias após a semeadura (DAS) do nabo forrageiro em amostras de solo com até 35 dias após a aplicação (DAA) dos herbicidas a campo.

Tabela 1 - Constantes de dissipação (k) e meia-vida $\left(\mathrm{t}_{1 / 2}\right)$ do herbicida S-metolachlor quando associado ao glyphosate ou paraquat

\begin{tabular}{|l|c|c|}
\hline Associação & $\begin{array}{c}\text { Constante de } \\
\text { dissipação }(\mathrm{k}) \\
\left(\mathrm{dia}^{-1}\right)\end{array}$ & $\begin{array}{c}\text { Meia-vida } \\
\left(\mathrm{t}_{1 / 2}\right)(\mathrm{dias})\end{array}$ \\
\hline S-metolachlor + paraquat & $2,02 \times 10^{-2}$ & 34 \\
\hline S-metolachlor + glyphosate & $2,44 \times 10^{-2}$ & 28 \\
\hline
\end{tabular}

Por meio da biodisponibilidade, verificouse que a cobertura vegetal evitou que o herbicida S-metolachlor atingisse o solo, pois apenas $2,0 \%$ do volume inicial aplicado foi detectado nos primeiros $5 \mathrm{~cm}$ do perfil do solo. Aos 1 e 14 DAA, não houve diferenças significativas entre as associações com glyphosate ou paraquat. Aos 5, 10, 21, 28 e 35 DAA, a disponibilidade do herbicida S-metolachlor foi maior quando associado ao paraquat (Figura 5). Trabalhos apresentados na literatura corroboram esses resultados. Um estudo revelou que o atrazine associado com paraquat foi mais eficiente do que quando associado com glyphosate, na transposição sobre as coberturas de azevém (Lolium multiflorum) e ervilhaca (Vicia villosa) (Isensee et al., 1998). Em trabalho no qual se utilizou cobertura viva de inverno formada pela associação de aveia-preta + 
ervilhaca, foi verificado que as porcentagens da dose inicial de atrazine associado com glyphosate ou com paraquat, detectadas no solo, foram de 41 e $61 \%$, respectivamente (Rodrigues et al., 2000). Isso demonstra que, em cobertura vegetal viva, o tipo de herbicida dessecante associado ao herbicida residual influencia diretamente a quantidade de composto residual disponível na solução do solo.

Por meio da cinética de dissipação (equações 1 e 2), verificou-se que a persistência do S-metolachlor foi maior quando o composto estava associado ao paraquat, em relação ao glyphosate, com constante de dissipação $(\mathrm{k})$ de 0,0202 dia $^{-1}(\mathrm{p}>0,003)$ e meia-vida $\left(t_{1 / 2}\right)$ de 34 dias ( $p>0,002)$. Os valores de meia-vida do S-metolachlor obtidos neste trabalho estão dentro dos limites normalmente observados para esse herbicida sob condições de campo. Os trabalhos demonstram que as meias-vidas do S-metolachlor e metolachlor variam entre 8 e 85 dias (Burgard et al., 1993; O’Connell et al., 1998; Dinelli et al., 2000; Laabs et al., 2002).

A degradação do metolachlor no solo ocorre através de processo microbiano (Accinelli et al., 2001). Trabalhos de campo e laboratório demonstram que a intensidade da dissipação desse herbicida está relacionada à biomassa e atividade microbiana no solo (Staddon et al., 2001; Accinelli et al., 2006).

Como o paraquat não possui efeito na população microbiana, pois apresenta elevada adsorção ao solo, os resultados de dissipação e meia-vida do S-metolachlor podem ser explicados pela presença ou ausência do glyphosate. Assim, é possivel que, na associação entre o S-metolachlor e o glyphosate, o dessecante aumente a biomassa e/ou estimule a atividade dos microrganismos que preferem metabolizar e degradar primeiramente o S-metolachlor, o que aumentaria a sua dissipação no ambiente em relação à aplicação de S-metolachlor na presença do paraquat.

O tipo de herbicida dessecante afeta a persistência do S-metolachlor quando aplicado sobre cobertura vegetal. Não há diferença entre aplicação simultânea e seqüencial dos herbicidas dessecantes e residuais. A persistência do S-metolachlor é maior na presença do paraquat do que na presença do glyphosate.

\section{LITERATURA CITADA}

ACCINELLI, C. et al. Atrazine and metolachlor degradation in subsoils. Biol. Fert. Soils, v. 33, n. 6, p. 495-500, 2001.

ACCINELLI, C. et al. Effects of the antimicrobial agent sulfamethazine on metolachlor persistence and sorption in soil. Chemosphere, v. 63, n. 9, p. 1539-1545, 2006.

ACCINELLI, C.; SCREPANTI, C.; VICARI, A. Influence of flooding on the degradation of linuron, isoproturon and metolachlor in soil. Agron. Sustain. Develop., v. 25, n. 3, p. $401-406,2005$

AHRENS, W. H. (Ed.). Herbicide handbook. 7.ed. Champaign: Weed Science Society of America, 1994. 352 p.

ANHALT, J. C. et al. Degradation of atrazine, metolachlor, and pendimethalin in pesticide-contaminated soils: Effects of aged residues on soil respiration and plant survival.

J. Environ. Sci. Health, Part B: Pestic., Food Contam., Agric. Wastes, v. 35, n. 4, p. 417-438, 2000.

BANKS, P. A.; ROBINSON, E. L. Soil reception and activity of acetochlor, alachlor, and metolachlor as affected by wheat (Triticum aestivum) straw and irrigation. Weed Sci., v. 34, n. 4, p. 607-611, 1986.

BANKS, P. A.; ROBINSON, E. L. The influence of straw mulch on the soil reception and persistence of metribuzin. Weed Sci., v. 30, n. 2, p. 164-168, 1982.

BAUMAN, T. T.; ROSS, M. A. Effect of three tillage systems on the persistence of atrazine. Weed Sci., v. 31, n. 3, p. 423-426, 1983.

BLASER H. U.; SPLINDER, F. Enantioselective catalysis for agrochemicals: the case history of the DUAL

MAGNUM herbicide. Chimia, v. 51, n. 6, p. 297-299, 1997

BURGARD, D. J. et al. Metolachlor distribution in a sandy soil under irrigated potato production. Weed Sci., v. 41, n. 4, p. 648-655, 1993.

BURGOS, N. R.; TALBERT, R. E. W. Weed control and sweet corn (Zea mays var. rugosa) response in a no-till system with cover crops. Weed Sci., v. 44, n. 2, p. 355-361, 1996.

CHAUHAN, B. S.; GILL, G.; PRESTON, C. Tillage systems affect trifluralin bioavailability in soil. Weed Sci., v. 54, n. 5 , p. $941-947,2006$.

DINELLI, G. et al. Comparison of the persistence of atrazine and metolachlor under field and laboratory conditions. J. Agric. Food. Chem., v. 48, n. 7, p. $3037-$ 3043, 2000.

Planta Daninha, Viçosa-MG, v. 26, n. 2, p. 385-393, 2008 
DOZIER, M. C. et al. Comparision of atrazine and metolachlor affinity for bermudagrass (Cynodon dactylon $\mathrm{L}$.) and two soils. Arch. Environ. Contam. Toxicol., v. 43, n. 3, p. $292-295,2002$.

\section{EMPRESA BRASILEIRA DE PESQUISA} AGROPECUÁRIA - EMBRAPA. Sistema brasileiro de classificação de solo. Brasília: Embrapa-SPI, 1999. 412 p.

FERREIRA, E. A. et al. Glyphosate no controle de biótipos de azevém e impacto na microbiota do solo. Planta

Daninha, v. 24, n. 3, p. 573-578, 2006.

FERRI, M. V. W. et al. Activity, adsorption, and lixiviation of acetochlor in soil under no tillage and conventional tillage: Influence of straw coverage. Comm. Soil Sci. Plant. Anal. v. 37, n. $5-6$, p. $627-640,2006$.

FERRI, M. V. W.; VIDAL, R. A. Persistência do herbicida acetochlor em função de sistema de preparo e cobertura com palha. Ci. Rural, v. 33, n. 3, p. 399-404, 2003.

FERRI, M. V. W. et al. Activity of the herbicide acetochlor in soil under no-till and conventional tillage system. Pesq. Agropec. Bras., v. 37, n. 12, p. 1697-1703, 2002.

GEBENDINGER, N.; RADOSEVICH, M. Inhibition of atrazine degradation by cyanazine and exogenous nitrogen in bacterial isolate M91-3. Appl. Microbiol. Biotechnol., v. 51, n. 3, p. 375-381, 1999.

GODOY, M. C. et al. Efeito da cobertura morta de milheto (Pennisetum americanum) sobre a eficácia do herbicida metribuzin no controle de Ipomoea grandifolia e Sida rhombifolia. Planta Daninha, v. 25, n. 1, p. 79-86, 2007

HANEY, R. L. et al. Soil carbon and nitrogen mineralization as affected by atrazine and glyphosate. Biol. Fert. Soils, v. 35, n. 1, p. $35-40,2002$

ISENSEE, A. R.; SADEGUI, A. M.; MYLAVARAPU, R. S. Impact of burn-down herbicides on atrazine washoff from vegetation. Chemosphere, v. 36, n. 1, p. 13-19, 1998

JAKELAITIS, A. et al. Atividade microbiana e produção de milho (Zea mays) e de Brachiaria brizantha sob diferentes métodos de controle de plantas daninhas. Planta Daninha, v. 25 , n. 1, p. $71-78,2007$

KRUTZ, L. J.; SENSEMAN, S. A.; HANEY, R. L. Effect of Roundup Ultra on atrazine degradation in soil. Biol. Fert. Soils, v. 38, n. 2, p. 115-118, 2003

LAABS, V. et al. Fate of pesticides in tropical soils of Brazil under field conditions. J. Environ. Qual., v. 31, n. 1, p. $256-268,2002$
LEVANON, D. et al. Mobility of agrochemicals through soil from 2 tillage systems. J. Environ. Qual., v. 22, n. 1, p. $155-161,1993$

LOWDER, S. W.; WEBER, J. B. Atrazine efficacy and longevity as affected by tillage, liming, and fertilizer type Weed Sci., v. 30, n. 3, p. 273-280, 1982.

MA, L. W.; SELIM, H. M. Predicting pesticide transport in mulch-amended soils: A two-compartment model. Soil Sci. Soc. Am. J., v. 69, n. 2, p. 318-327, 2005

MA, Y.; LIU, W. P.; WEN, Y. Z. Enantioselective degradation of rac-metolachlor and S-metolachlor in soil. Pedosphere, v. 16, n. 4, p. 489-494, 2006.

MACIEL, C. D. G.; VELINI, E. D. Simulação do caminhamento da água da chuva e herbicidas em palhadas utilizadas em sistema de plantio direto. Planta Daninha, v. 23, n. 3 , p. $471-482,2005$.

MERSIE, W. et al. Degradation of metolachlor in bare and vegetated soils and in simulated water-sediment systems. Environ. Toxicol. Chem., v. 23, n. 11, p. 2627-2632, 2004.

MOORMAN, T. B. et al. Organic amendments to enhance herbicide biodegradation in contaminated soils. Biol. Fert. Soils, v. 33, n. 6, p. 541-545, 2001.

MOSER, H.; RIHS, G.; SAUTER, H. The influence of atropisomerism and chiral center on the biological-activity of metolachlor. Z. Naturforsch. Bodenkd., v. 37, n. 4, p. 451$462,1982$.

O'CONNELL, P. J.; HARMS, C. T.; ALLEN, J. R. F Metolachlor, S-metolachlor and their role within sustainable weed-management. Crop Protec., v. 17, n. 3, p. 207-212, 1998.

PAUL, E. A.; CLARK, F. E. Soil microbiology and biochemistry. 3.ed. San Diego: Academic Press, 1996 $340 \mathrm{p}$.

REDDY, K. N. et al. Chlorimuron ethyl sorption and desorption kinetics in soils and herbicide-desiccated cover crop residues. J. Agric. Food. Chem., v. 43, n. 10, p. 27522757, 1995

RODRIGUES, B. N.; LIMA, J.; YADA, I. F. U. Retenção pela palhada, de herbicidas aplicados em pré-emergência na cultura do milho, em plantio direto. R. Bras. Herb., v. 1, n. 2, p. $123-128,2000$.

SELIM, H. M.; ZHOU, L.; ZHU, H. Herbicide retention in soil as affected by sugarcane mulch residue. J. Environ.

Qual., v. 32, n. 4, p. 1445-1454, 2003.

SEYBOLD, C. A.; MERSIE, W.; MCNAMEE, C. Anaerobic degradation of atrazine and metolachlor and metabolite formation in wetland soil and water microcosms. J. Environ. Qual., v. 30, n. 4, p. 1271-1277, 2001 
SORENSON, B. A.; SHEA, P. J.; ROETH, F. W. Effects of tillage, application time and rate on metribuzin dissipation. Weed Res., v. 31, n. 6, p. 333-345, 1991.

SPINDLER, F. et al. Enantioselective catalysis for agrochemicals: Synthetic routes to (S)-metolachlor, (R)metalaxyl and (alpha S,3R)-clozylacon. Pestic. Sci., v. 54, n. 3, p. 302-304, 1998

STADDON, W. J.; LOCKE, M. A.; ZABLOTOWICZ, R. M. Microbiological characteristics of a vegetative buffer strip soil and degradation and sorption of metolachlor. Soil Sci. Soc. Am. J., v. 65, n. 4, p. 1136-1142, 2001.

TEASDALE, J. R. et al. Influence of hairy vetch residue on atrazine and metolachlor soil solution concentration and weed emergence. Weed Sci., v. 51, n. 4, p. 628-634, 2003.
THEISEN, G.; VIDAL, R. A.; FLECK, N. G. Redução da infestação de Brachiaria plantaginea em soja pela cobertura do solo com palha de aveia-preta. Pesq. Agropec. Bras., v. 35, n. 4 , p. $753-756,2000$.

TUFFI SANTOS, L. D. et al. Exsudação radicular do glyphosate por Brachiaria decumbens e seus efeitos em plantas de eucalipto e na respiração microbiana do solo. Planta Daninha, v. 23, n. 1, p. 143-152, 2005.

VIDAL, R. A.; FLECK, N. G. Inibidores do crescimento da parte aérea. In: VIDAL, R.A.; MEROTO JR., A. (Orgs.).

Herbicidologia. Porto Alegre: Evangraf, 2001. p. 123-130.

WEED, D. A. J. et al. Dissipation and distribution of herbicides in the soil profile. J. Environ. Qual., v. 24, n. 1, p. 68-79, 1995. 